\title{
Nevus of Ota: The Unusual Birthmarks: A Case Report
}

\author{
TAMANNA BEGUM ${ }^{1}$, PUNAM RAI ${ }^{2}$, GURSHARAN KAUR ${ }^{3}$, RAFIQUL ISLAM $^{4}$, SADIKA KADIR $^{5}$
}

\begin{abstract}
:
Nevus of Ota is a benign congenital melanosis bulbi. It is a rare entity, commonly seen in female. It occurs among Asians and Africans. It mainly involves the eye, skin and ear. It is predominantly unilateral but could be bilateral. Typical clinical manifestation was present in our case, however, biopsy is the investigation of choice. There is no specific treatment but ophthalmological and dermatological intervention can be opted. Outcome is remarkably good. Here we reported a case of a child with Nevus of Ota who was primarily admitted at paediatric department with enteric fever. We managed her conservatively and followed up in specific department.
\end{abstract}

Key words: Nevus of Ota, Unilateral, Birthmarks.

\section{Introduction:}

Nevus of Ota is benign melanocytic pigmentary disorder also known as "congenital melanosis bulbi". 1,2 Nevus of Ota which was first reported by Hulke in 1860 before Ota and Tamina description in 1939 is characterized by unilateral, patchy, irregular, blue-black or grey discoloration of skin supplied by ophthalmic and maxillary divisions of trigeminal nerve, especially the periorbital region, temple, malar prominence, forehead and nose. ${ }^{3}$ This condition should be differentiated from Hori nevus which is acquired and does not have mucosal involvement. ${ }^{4}$ Around $50 \%$ of cases occur at birth, while the remaining occur during puberty and adulthood. Initial hyperpigmentation may be present as light in color with continued hyper pigmentation as the individual ages. ${ }^{5,6}$ It is rare entity reported more commonly in female patients with $M: F=1: 4.8$, usually unilateral with $5-10 \%$ cases being bilateral. $4,7,8$ It also occurs predominantly in people of Asian and African descent. ${ }^{9}$ Although whites are the least likely race to develop Nevus of Ota, they are most likely to develop malignant melanoma associated with this condition. ${ }^{10}$

1. Professor, Department of Paediatrics, Z.H. Sikder women's medical college \& hospital, Dhaka

2. Intern Doctor Z.H. Sikder women's medical college \& hospital

3. Intern Doctor Z.H. Sikder women's medical college \& hospital

4. Associate Professor, Department of Paediatrics, Z.H. Sikder women's medical college \& hospital

5. Assistant Professor, Department of Paediatrics, Z.H. Sikder women's medical college \& hospital

Correspondance: Dr. Tamanna Begum, Professor and Head of Department of Paediatrics, Z.H Sikder women's medical college and hospital, Dhanmondi, Dhaka. Contact no: 01711637371, email: dr_tbegum@yahoo.com

Received: 16/01/2020
There are no known risk factors for Nevus of Ota, but patients with Nevus of Ota are at Risk involving eye: Due to invasion of melanocytes blocking the drainage of aqueous - Glaucoma and Malignant melanoma of uveal tract, orbit (choroid), Risk involving skin: Malignant melanoma of the involved skin and Risk involving ear: Ipsilateral sensorineural hypoacusia ${ }^{11-13}$ Currently there is no definitive cause of Nevus of Ota. Several hypothesis have been suggested: One hypothesis is that it is caused by failure of migration of melanocytes from neural crest cells to their normal location within the basal layer of the epidermis. Genetic mutations have been noted, including receptor tyrosine kinase (c-KIT) positive, guanin nucleotide-binding protein $\mathrm{G}(\mathrm{q})$ subunit alpha (GNAQ) mutations, as well as activating GTpase RAS pathway mutations. Ubiquitin carboxyl-terminal hydrolase (BAP1) and tumor protein p53 (TP53) mutations have also been demonstrated on whole genome sequencing of the nevi during tumor evolution. Additional hypothesized causes include previous radiation exposure and hormonal factors. ${ }^{10,12,13}$

\section{Case Report}

A 10-year-old female patient visited to the outpatient department of Paediatrics with fever and cough since 3 days. General examination of the patient revealed the presence of asymptomatic blue-grey lesion on the face (Fig.1) including eye on the right side (Fig.2). On eliciting specific history regarding sclera and facial discoloration, the patient revealed that it was present since birth, family history was non-contributory. Her parents were non-consanguineous. The discoloration 
on her face involved the forehead, temple, malar, periorbital area and sclera (Fig.3). No other pigmentation abnormalities were noticed on any other site during her physical examination. There is no history of alteration in its size and no photosensitivity. She had not taken any treatment for this. The patient was asymptomatic with no effect on vision, sensory changes and hearing. Oral examination revealed good oral hygiene and no involvement of buccal mucosa or palate.

The patient was referred to Dermatologist. On consultation, a unilateral diffuse, homogenous, blueblack macular pigmentation over the right side of the face, involving right side of forehead, temple, maxilla, infraorbital area and eye. The border of the lesion was irregular. Dermatologist confirmed the diagnosis of Nevus of Ota. Ophthalmological examination using slit-lamp biomicroscopy revealed blue-grey pigmentation in the sclera, visual acuity 6/6, pupilnormal, iris hyperchromic and mamillation and conjunctival subepithelial melanocytosis. They too agreed with the diagnosis of Nevus of Ota (Fig.5). On ENT consultation, no hearing loss, Rinne's test was positive in both side and Weber's test was centralized.

\section{Investigation:}

Biopsy is the choice for confirmation of the diagnosis, but it was not done because clinical findings were typical, patient was from lower socio-economic status and didn't give any consent.

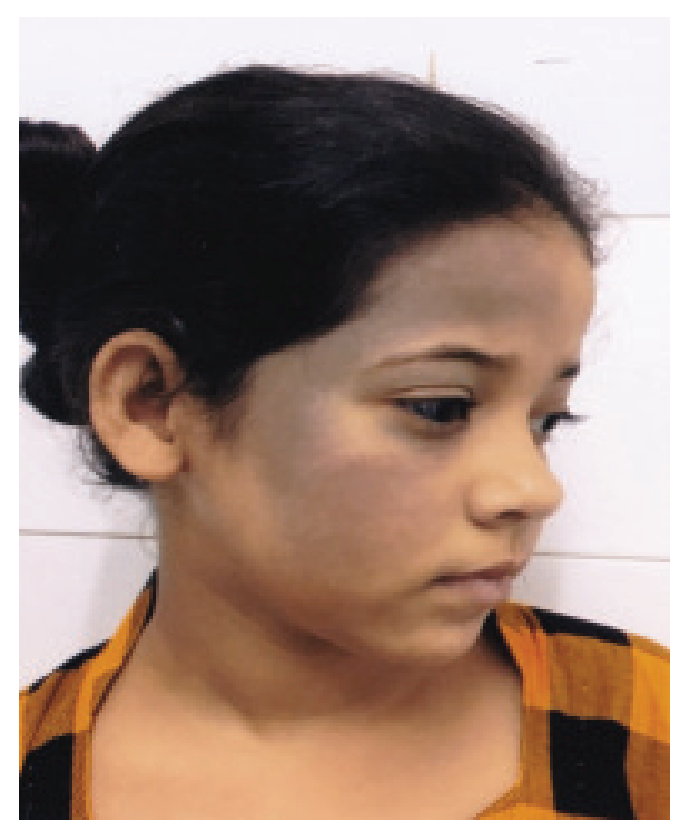

Fig.1. Blue gray lesion in the right side of the face including fore head and neck

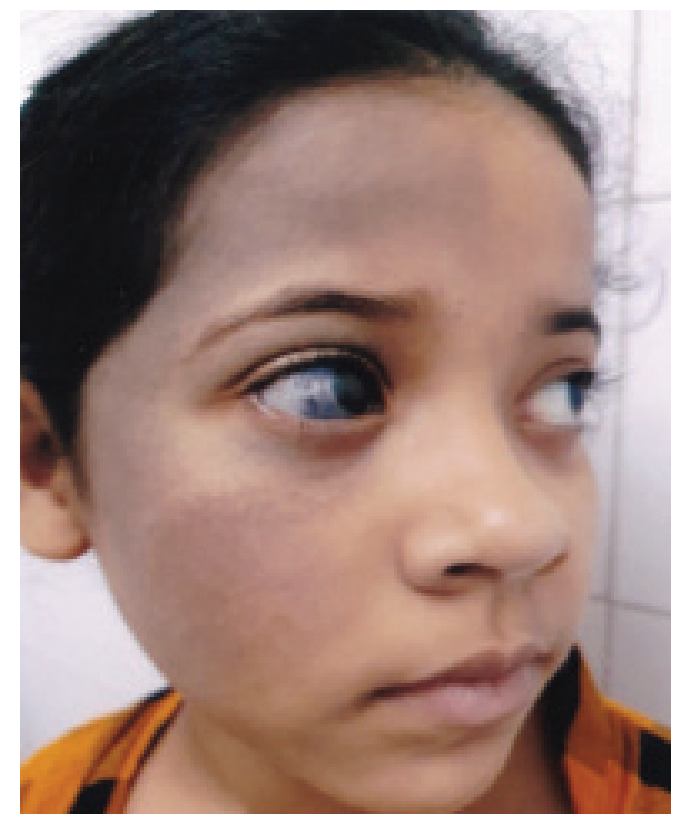

Fig-2. Picture showing the blue-gray lesion in right side of face and right eye.

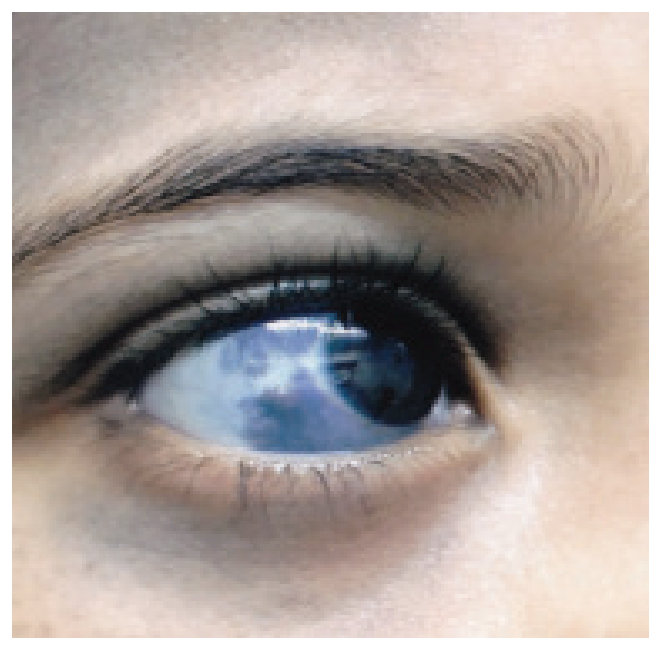

Fig-3. Blue gray pigmentation in the sclera

\section{Differential diagnosis:}

Mongolian spot, Melasma, Blue nevus, Drug induced hyperpigmentation, Sturge Weber syndrome, Neurofibromatosis, Multiple haemangioma, Fascial Café-au-lait patch

\section{Treatment options:}

Dermatologic treatment: Laser therapy: QS ruby (595 $\mathrm{nm})$, QS alexandrite $(755 \mathrm{~nm}), \mathrm{QS} \mathrm{Nd}$ : YAG (1064 $\mathrm{nm})$. The Q-switched $1064 \mathrm{~nm} \mathrm{Nd-YAG}$ is an ideal choice as it reduces the risk of epidermal injury and pigmentary alterations. ${ }^{14}$ Some other options are: 
Cryotherapy, Surgical excision, Carbon dioxide, Argon, Chemical peeling, Dermabrasion, and topical hydroquinone based bleaching agents. Use of cosmetic products such as camouflaging creams, foundation and concealers to mask discolorations. For more extensive lesions or metastatic transformation, the combination of complete excision, adjuvant radiation therapy or chemotherapy may be used. $^{3}$

Ophthalmologic treatment: No specific treatment is required as long as visual acuity and pupils are normal. But, periodic 6 monthly review is required to see visual deterioration, iris change and glaucomatous change.

Outcome and follow up: Q-switched lasers are safe and effective for lightening nevi of Ota. Healing is quite rapid with mild side effects such as purpura, erythema, and edema, that usually resolve after a few days. However, changes such as hyperpigmentation or hypopigmentation occur more frequently. The response to laser treatment are dependent on lesion. Overall, laser therapy is very effective and recurrence is rare. ${ }^{15}$

Regular follow-up is mandatory for persons with Nevus of Ota. Screening for the development of malignant melanoma should also be done, using slitlamp biomicroscopy and papillary dilatation for ophthalmoscopy. It is recommended that these patients be reviewed biannually by a dermatologist and ophthalmologist. ${ }^{11}$

\section{Discussion:}

Nevus of Ota represents a unilateral dermal melanosis in the distribution of the trigeminal nerve. ${ }^{16}$ The exact etiology is still unknown. ${ }^{10}$ In our case a congenital unilateral blue-grey like lesion was present on the right side of face which is similar to findings of other literatures. ${ }^{3,4,15}$ Female $(80 \%)$ are affected more frequently than male, and it can be unilateral or bilateral, but unilateral involvement is common (90$95 \%)$. Rare cases of sensory hearing loss have been reported, but not present in our case. ${ }^{17}$ Extracutaneous sites like eyelids, sclera, and conjunctiva, have also been involved, as seen in our case. Spontaneous regression does not occur, although the intensity of the pigmentation may vary in relation to menstruation, fatigue or weather. ${ }^{12}$

Mishima classified nevus of Ota depending on the extent and distribution of pigmentation into three types: Type I: Upper and lower eyelids and zygomatic area, Type II: Eyelids, zygomatic area, and base of nose and Type III: Affecting the first and second division of trigeminal nerve. Thus, our case will correspond to Type III classification. ${ }^{13}$

Histopathology of affected skin shows the presence of benign dendritic melanocytosis containing melanin in the dermis. Other observation is that the melanosomes in cells cultured from Ota's nevus are in part abnormal, almost mimicking those found in dysplastic nevi and melanoma. ${ }^{16,18}$

Diagnosis of nevus of Ota can be made based on its striking clinical characteristics but other entities that need to be considered like Nevus of Ito which has features similar to that of Ota's nevus, except that Ito's nevus occurs along the distribution of the posterior supraclavicular and lateral cutaneous branchial nerves. The Mongolian spot is congenital and involves the lumbosacral area and frequently regresses at about the age of 5-7 years. Acquired Bilateral Nevus of Ota-like Macules is clinically distinguished by speckled or coalescent brownishblue or slate-gray pigmentation over the face with no oral mucosa and eye involvement and histologically by diffuse upper dermal melanocytes. Our patient, however had no pigmentation of nail, perioral pigmentation, lentigines, and deafness, thus, exclusion of above pathologies was made. ${ }^{19}$ Skin biopsies are required only if clinical changes are suspected of malignant transformation ${ }^{15}$

Various therapies are suggested in the literatures. ${ }^{3,4,15}$ Cosmetic cover-up products can be used for camouflage only. Combined dermabrasion and carbon dioxide lasers provide good result. Qswitched laser therapy is very effective and recurrence is rare. Topical Tretinoin, hydroquinone, and corticosteroid creams can be used for postinflammatory hyperpigmentation. Other options are epidermal peeling, dermabrasion with autologous cultured epithelium grafting, and the combination of sequential dry ice. All options of treatment were suggested to our patients. ${ }^{20,21,22}$

\section{Conclusion:}

Nevus of Ota is a benign dermal melanocytosis, presenting at birth or by adolescence, that tend to remain unchanged throughout life but can darken overtime. Although it is benign, patients do carry risk of developing glaucoma and malignant cutaneous 
and/or ocular melanoma. Thus, biannual review with ophthalmology and dermatology is recommended. Treatment can be performed for cosmetic reasons. The psychological impact of the lesions is high, and early treatment would considerably reduce the stress later in life. A multidisciplinary screening involving dermatologist, ophthalmologist, dentist and otolaryngologist is suggested for these patients.

\section{References:}

1. Fitzpatrick TB, Kitamura H, Kukita A, Zeller R. Ocular and dermal melanocytosis. AMA Arch Opthalmol 1956;56:830-32

2. Patel BC, Egan CA, Lucius RW, Gerwels JW, Mamalis N, Anderson RL. Cutaneous malignant melanoma and oculodermal melanocytosis (Nevus of Ota): Report of a case and review of the literature. J Am Acad Dermatol 1998;38: 862-65

3. Ravi Prakash SM, Sankalp V, Amit kS, Udita S. "Nevus of Ota: the unusual birthmarks: a case review" BMJ case reports 2013: March (01). doi: 10.1136/bcr-2013-008648

4. Sharma S, Jha AK, Mallik SK. Role of Q-switched ND:YAG laser in nevus of Ota: A study of 25 cases. Indian J Dermatol 2011;56: 663-5

5. Murakami F, Baba T, Mizoguchi M. Ultravioletinduced generalized acquired dermal melanocytosis with numerous melanophages. Br J Dermatol 2000; 142:184-6

6. Stanford DG, Georgouras KE. Dermal melanocytosis: a clinical spectrum. Aust J Dermatol 1996; 37:19-25

7. Ota M. Nevus fuscoceruleus opthalmomaxillaris. Tokyo Med J 1939; 63:1243-5.

8. Wilcox JC. Melanamatosis of skin and central nervous system. Am J Dis Child 1939; 57:391.

9. Rapini RP, Bolognia JL, Jorizzo JL. Dermatology. 20007: 2 :1720- 22.
10. Shaffer, D., Walker, K., \& Weiss, G. R. Malignant melanoma in a hispanic male with nevus of Ota. Dermatology, 1992;185:146-150

11. Cronemberger S, Calixto N, Leite HF, Oftalmol RB, Nevus of Ota: Clinical opthalmological findings. Rev Bras Oftalmol 2011; 70:278-83

12. Hanna, C. (2018). Nevus of Ota: Treatment, Eye, Removal, Glaucoma, and More. Healthline.

13. Vivancos A, Caratu G, Matito J, Munoz E, Ferrer B, Hernandez J . Genetic evolution of nevus of Ota reveals clonal heterogeneity acquiring BAP 1 and TP 53 mutations. Pigment cell \& melanoma res, 2016:29: 247-53.

14. Redkar, N.N., Rawat, K.J.,Warrier, S., \& Jena, A. Nevus of Ota. Journal of the Association of Physicians of India, 2016;64:70.

15. Maheshwari R, Desai V, Sunil Kumar M V, Gaurav I. Unilateral nevus of Ota: A Case report of oculodermal melanocytosis. J Dent Allied Sci 2016; 5:39-42

16. Mauropoulos JC, Cohen BA. Disorders of pigmentation. In: Cohen BA, editor. Pediatric dermatology. $4^{\text {th }}$ ed. Philadelphia: Elsevier Saunders. P. 148

17. Paul TF. The Nevus of Ota. New York Eye Cancer Center.2018.

18. Singh P, Bagewadi A, Keluskar V, and Shetti A. "Nevus of Ota involving palate: case reports and review," J Indian Acad Oral Med Radiol,2007,19: 441-45.

19. Rathi S. "Bilateral nevus of Ota with oral mucosal involvement," Indian Journal of Dermatology, Venereology and Leprology.2002, 68:104.

20. Chan HH, Kano T. Nevus of Ota: Clinical aspect and management. Skinmed 2003;2: 89-96

21. Sekar S, Kuruvila M, Pai HS. Nevus of Ota: a series of 15 cases. Indian J Dermatol Venereol Leprol 2008;74:125-7

22. Alsaif $\mathrm{F}$, Alshahwan $\mathrm{H}$. Bilateral nevus of Ota associated with Turner Syndrome. J Saudi Soc Dermatol Dermatol Surg 2010;15:33-6. 